Kuo E Chen, 2020

Volume 5 Issue 3, pp. 916-924

Date of Publication: 26 th February 2020

DOI- https://doi.org/10.20319/pijss.2019.53.916924

This paper can be cited as: Kuo, C., E Chen, F., (2020). Action Research on Students' Creative Inventions in Vocational High School. PEOPLE: International Journal of Social Sciences, 5(3), 916-924.

This work is licensed under the Creative Commons Attribution-Non Commercial 4.0 International License. To view a copy of this license, visit http://creativecommons.org/licenses/by-nc/4.0/or send a letter to Creative Commons, PO Box 1866, Mountain View, CA 94042, USA.

\title{
ACTION RESEARCH ON STUDENTS' CREATIVE INVENTIONS IN VOCATIONAL HIGH SCHOOL
}

\author{
Chiu-Cheng Kuo \\ Graduate school of Technological and Vocational Education, National Yunlin University of Science \\ and Technology, Yunlin, Taiwan \\ ccheng0976@gmail.com
}

Fei-Chuan Chen

Graduate school of Technological and Vocational Education, National Yunlin University of Science and Technology, Yunlin, Taiwan

chenfj@yuntech.edu.tw

\begin{abstract}
Because the bicycle lacks lighting equipment, there is no indicator light when steering and braking, thus making it is easy to cause a rear vehicle collision and form a casualty, especially at night. In view of this, this study focused on the safety of bicycles at night, taking vocational high school students, using the existing equipment of the school, combined with relevant curriculum theory and practice, creative thinking and production of "Bicycle safety display device", the LED projection lamp installed in the back seat, with the back of the bicycle rider as the projection screen, can display the enlarged pattern of left and right turn and brake, so that the rear vehicle can be clearly identified to reduce the incidence of accidents. The conclusions of this study are as follows:(1)The study found that the production of the "Bicycle Safety Display Device" enhanced students' understanding and application of relevant courses; (2) The study found that the production of "Bicycle Safety Display Device" enhanced the student's circuit design and production capabilities; (3) Through participation in the project, the students generally came to believe that the production of the
\end{abstract}


"Bicycle Safety Display Device" can unite the team's centripetal force and contribute greatly to the improvement of cooperative learning, and problem solving and innovative invention capabilities; (4) The finished product of this study is useful for the night driving safety of the bicycle.

\section{Keywords}

Bicycle Lighting, Bicycle Driving Status Display, Bicycle Night Driving Safety, Creative Thematic Production

\section{Introduction}

Einstein once said: "Imagination is more important than knowledge". Knowledge is limited, but rich imagination can create unlimited possibilities, innovation is the key capability that students need to adapt to the rapidly changing world of the future, however, the ability to innovate and invent cannot be produced in theoretical research, it must be generated through creative thinking, hands-on implementation, and continuous accumulation of experience. In order to cultivate students' ability to innovate, it is necessary to develop special production and flexible courses in vocational high schools so that students can learn from each other according to their interests and cultivate their core competence. In the "hands-on" process, in addition to helping students learn knowledge, it is more important that students must have the ability to innovate, think independently and solve problems (Yang \& Lin, 2018). Moreover, Taiwan's problem of the declining birth rate has been serious in recent years, affecting the labor and employment market, and making it necessary for schools to change the educational philosophy and the direction of the curriculum, improve the employability and productivity of students, and solve problems resulting from the impact of fewer children in Taiwan. The talent gap in Taiwan is quite serious, and without a positive response, it will be difficult to compete with other countries (Zhou, 2016).

\subsection{Research Motivation}

Due to the lack of lighting equipment for bicycles, there is no indicator light when turning and braking. At night, this can easily lead to a collision and casualties. In order to reduce the occurrence of such incidents, we guided students to carry out the creative thinking and production of the "Bicycle Safety Display Device", and to use the existing equipment and materials of the school, combined with the theory and practice of the curriculum, using the laser light as the projection light source, designing the brakes, turning the left and right symbols, and using the back of the bicycle rider as the projection screen, showing an enlarged and obvious graphic display, so that the bicycle can still make the back clear when the nighttime light is insufficient, identify the movements of the 
bicycle and increase alertness to reduce the possibility of chasing and ensure the safety of the cyclist. Innovation is the main axis of today's education and a key issue in the development of vocational education reform (Huang, 2017).

\subsection{Research Purposes}

\subsubsection{Familiarise Students with the Single-Chip 8051 Course and its Practical Applications}

\subsubsection{Develop Students' Circuit Design and Production Capabilities}

\subsubsection{Develop a Practical "Bicycle Safety Display Device"}

\subsubsection{Remind Everyone to Pay Attention to Bicycle Safety}

\subsubsection{Develop Students' Problem-Solving Skills}

\subsubsection{Supervise Students in Cooperating and Learning so as to form a Team Spirit}

\subsubsection{Enhance Students' Ability to Innovate and Invent}

In the future, our schools should adjust the content of education and bring it in line with the needs of the market, thereby shortening the gap with the market, breaking the boundaries of the department, and strengthening cross-disciplinary cooperation (Zeng, 2018). We hope that through the school curriculum and equipment, students will be encouraged to brainstorm, be creative, and often come up with innovative ideas, activate the learning process, and integrate with industry to propose ideas or products that are beneficial to people's lives.

\section{Method}

This study used an action research method and used the PDCA cycle model to perform planning and control quality.

Plan- Four students were selected to participate in the project. First, students were encouraged to form creative ideas. Secondly, relevant literature and materials were collected, and the theme was decided and the overall planning was made.

Do- Following division of labor and cooperation, the plan was implemented.

Check- The researchers regularly reviewed the progress of the work, assessed the completion rate of the work, and identified problems and analysed their causes.

Act- Based on the results of the inspection, the defect improvement was carried out, the steps were repeated following the P-D-C-A-P... procedure, the system was processed, and the plan was made more comprehensive.

This study hoped to guide students in participating and executing projects through systematic processing and operation, regular planning, execution, verification and improvement. Finally, the 
results of the implementation of the project were reviewed along with the creative inventions produced by the students; also, an analysis of the interviews with the students was conducted.

\section{1 "Bicycle Safety Display Device" Construction (Figure 1, 2)}

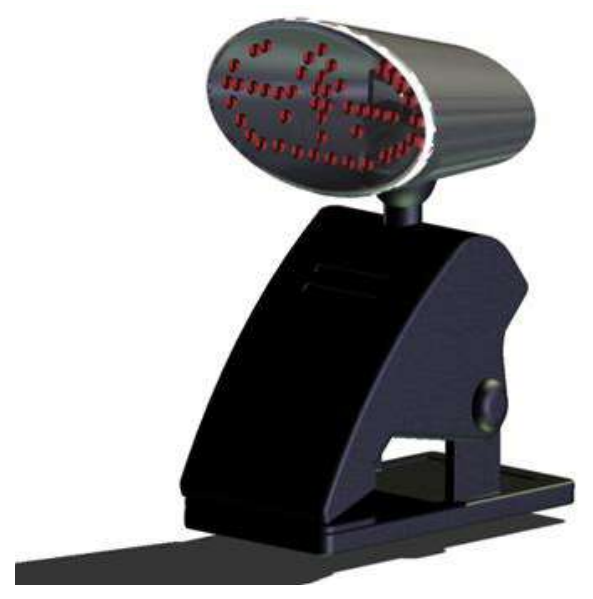

Figure 1: Appearance of the Idealized Finished Product

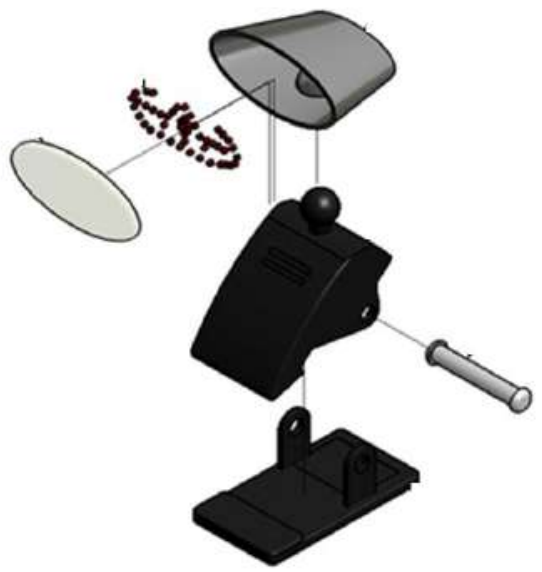

Figure 2: Idealized Product Exploded View

\section{2 "Bicycle Safety Display Device" Function (Figure 3, 4, 5)}

This research works with the back of the bicyclist as the projection screen, which can be enlarged to increase the display effect, so that the rear vehicle can be clearly identified. The device has a single chip 8051 as the main control element, the left and right rotation limit switches and the brake sensing switch as input components; the display module acts as the output component.

When the knight turns left, touch the left turn limit switch to drive the display module, and the projected left turn arrow pattern is on the back of the knight and blinks continuously. 


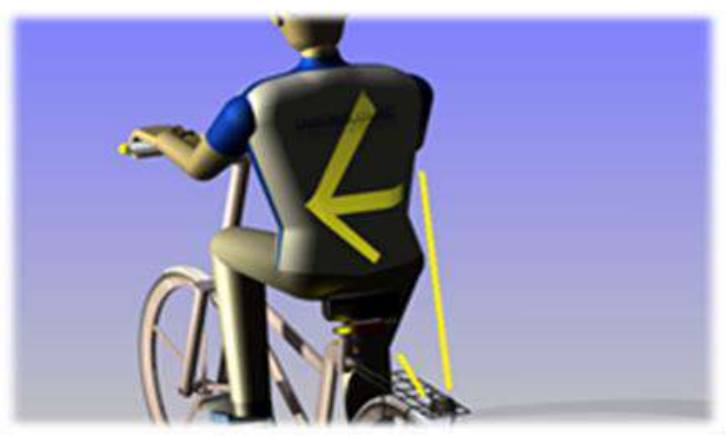

Figure 3: Turn Left

When the knight turns right, touch the right turn limit switch to drive the display module, and the projected right turn arrow pattern is on the back of the knight and continues to flash.

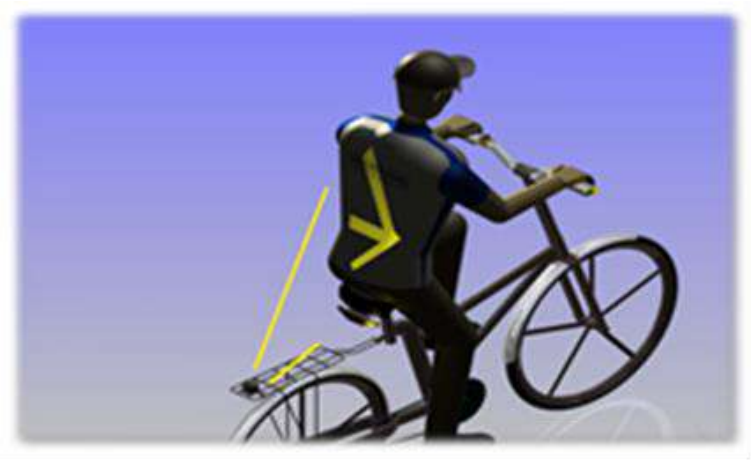

Figure 4: Turn Right

When the knight brakes, the brake sensor switch is activated to drive the display module, and the enlarged brake pattern is projected on the back of the knight and continues to flash.

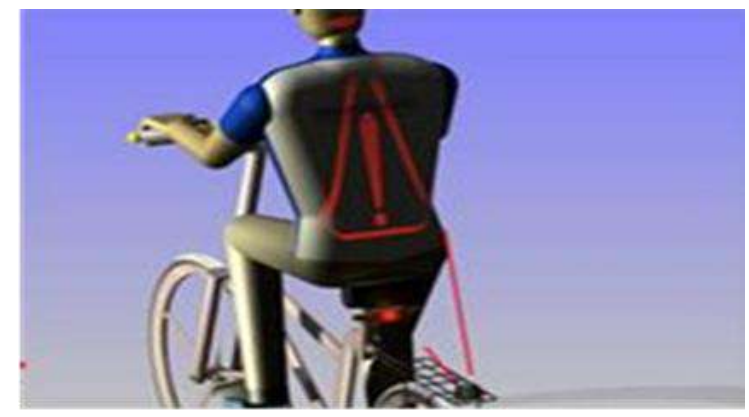

Figure 5: Brake Light

\section{Results and Discussion}

Talent cultivation is not enough for good school efforts; it is necessary for industry to work together with schools to achieve results (Rao \& Lai, 2017). Thematic production courses allow students to practice, increases their interest in learning, and enhances their innovative invention skills. If we can seek cooperation from the industry, provide sophisticated instruments and 
equipment, and coordinate teaching with technical teachers, we will be able to achieve fruitful results.

\section{1 "Bicycle Safety Display Device" Practical Value}

3.1.1 The projector can greatly improve the visibility of the bicycle.

3.1.2 The left and right turns and the brake symbol make it easy for the rear car to recognize the intention of the bicycle.

3.1.3 With the back of the knight as a projection screen, enlarged and clear images can be displayed.

3.1.4 The structure is simple and easy to mass produce.

\subsection{Analysis of Students' Interviews}

In order to understand the effectiveness of this study, we conducted interviews with participating students and used their opinions as a basis for reviewing improvements. The opinions and experiences provided by the students are summarized as follows:

3.2.1 In order to decide the topic, we must constantly think and imagine.

3.2.2 When we want to make this topic creative, we must work hard to study the single-chip 8051 related books.

3.2.3 Due to the limited equipment, we often look for alternatives.

3.2.4 We have a better understanding of electronic components and board soldering.

3.2.5 There were many difficulties in the process, and we learned the spirit of teamwork and the way to solve problems.

3.2.6 Through this creative theme production, we could pay more attention to the safety of bicycles driving at night.

3.2.7 Unfortunately, because of the limited equipment and funding, it was impossible to present a perfect work; if the industry can provide equipment and funds, the project will be easier to implement.

3.2.8 We believe that our creative and innovative curriculum will enhance our ability to innovate.

\subsection{Recommendation}

\subsubsection{Accelerate Curriculum Reform and Enhance Students' Interest in Learning}

Due to the changes of the times, teachers should abandon the teaching method of one-way teaching, return the dominance of learning to students, and guide students toward a middle path, where they learn to think and think in a balanced manner. In the process of cultivating "makers" in education, combining the education system to promote the Maker spirit and join the do-it-yourself work has become an important topic today (Cao, 2018). 


\subsubsection{Conduct Industry-School Cooperation to help Students Understand the Pulse of the Industry}

During 12 years of state education, when promoting information technology learning, there will be obstacles such as the shortage of school information equipment, education field teachers, and the digital gap in rural areas (Gao \& Tsai, 2018). Students often have unlimited imagination and creativity, but because of limited equipment in the school and the gap with industry, the development of students is inhibited. If industry provides excellent equipment and technical guidance, this will enhance the effectiveness of students' creative inventions.

\subsubsection{Improve Finished Product and Reduce Volume}

Due to equipment and funding problems, the actual works of this topic have a gap with the ideals, and only the expected function of the work is dominant, while the appearance and size are not satisfactory, only seek to achieve the purpose of educating students. If we can improve the device's appearance and reduce its volume, this will greatly enhance the device's effectiveness and benefit the rider.

\section{Conclusion}

Through the division of labor, cooperation, creativity, and hands-on work, the project has undergone many twists and turns, but the study finally overcame several difficulties to complete the task. The conclusions of this study are as follows:

4.1 This study found that the production of the "Bicycle Safety Display Device" can enhance students' understanding and application of relevant courses. The development of this topic was based on the single-chip 8051 as the main control component, and students being familiar with the structure, principle, and programming method of the single-chip 8051 was of great help to the understanding of the single-chip 8051 course.

4.2 This study found that the production of the bicycle safety display device can enhance the student's circuit design and production capabilities. Through the production of this topic, students designed circuits, understood the functions of various electronic components, and soldered circuits by themselves, thereby greatly improving their circuit design and production capabilities.

4.3 From the results of interviews with students, it is clear that students who participated in the project generally believed that the production of the "safety display device for bicycles" can unite the team's centripetal force and greatly contribute to the improvement of cooperative learning, problem solving, and innovation and invention capabilities. 
4.4 The results of this research have helped the bicycle rider's driving safety. The work on this topic involved using the back of the cyclist as the projection screen, which allows one to get an enlarged pattern, increase the display effect, and display the state of left turn, right turn and braking effectively, so that the rear car can be clearly identified, and bicycle safety at night can be greatly improved.

4.5 Due to the limited equipment in the school, the product size is too large, the appearance is not perfect, and there is a big gap with the idealized product, Microchips and precision equipment are recommended to reduce product size and beautify the appearance. It is only for students to do it and improve their ability to innovate and invent.

4.6 It is best to have students from different fields of expertise, cross-disciplinary cooperation. Seeking industry support, providing technical teachers and equipment.

The maker spirit creates initiative, encourages sharing and cooperation, and starting from fun, any idea can be made (Yang \& Lin, 2018). In addition, students learn knowledge transfer, hands-on implementation, innovative thinking, and more importantly, participation and interest in the learning process (Zhang, 2018). Teaching innovation and activating the curriculum content are important in promoting action learning programs (Lin \& Xu, 2014). In order to cope with the rapidly changing world in the 21 st century, we must cultivate students' instincts to adapt to the environment; hands-on is the main way of establishing key capabilities, encouraging students to use their imagination, and practice, and realizing concepts with continuous learning and growth.

\section{Acknowledgments}

This kind of action research can be carried out smoothly, first of all, i would like to thank the participating students who are always full of enthusiasm, full of ideas, and able to act actively, although they encounter many setbacks, they can overcome them, fully demonstrate the ability of teamwork; and then thank the Vocational High School where i work, provide venues and equipment, so that students can concentrate on research, hoping to enhance students' creative ability and teamwork spirit, and the theory and practice combined, I hope that he can contribute to society.

\section{References}

Cao, X. Y. (2018). A case study of environmental art education courses incorporating Maker spirit. Taiwan Education Review Monthly, 7(2), 10-24. 
Gao, J. J. \& Tsai, M. X. (2018). Talking about the obstacles and strategies of the 12 years of state education in the implementation of information technology in the field of science and technology in the national primary and secondary schools. Taiwan Education Review Monthly, 7(2), 80-84.

Huang, Y. X. (2017). Innovative teaching combines the relevance of the industry. Taiwan Education Review Monthly, 6(8), 06-09.

Lin, Y. F. \& Xu, Y.J. (2014). Several thoughts and suggestions on action learning. Taiwan Education Review Monthly, 2014, 3(7), 63-66..

Rao, D. Q. \& Lai, M. H. (2017). Talking about the cultivation of industrial talents from corporate social responsibility. Taiwan Education Review Monthly, 2017, 5(8), 10-18.

Yang, M. S. \& Lin, Y. X. (2018). Maker Education Theory and Practice. Taiwan Educational Review Monthly, 7(2), 29-38.

Zhang, Y. S. (2018). STEAM Maker integrates across the domain and practices 12 years of state education. Taiwan Education Review Monthly, 7(2), 01-05.

Zeng, Z. C. (2018). Looking at the problem of brain drain in Taiwan from the perspective of supply demand. Teacher's Monthly, 2018.01, 15-22.

Zhou, Z. Y. (2016). Faced with the talented inheritance and innovation of the younger generation. Teacher's Monthly, 583, 69-72. 